\title{
NUMERICAL STUDY ON HEAT TRANSFER CHARACTERISTICS AND PERFORMANCE OF DOUBLE-PASS FLAT PLATE SOLAR AIR HEATERS
}

\author{
Ali K. Abdel-Rahman \\ Associate Professor, Department of Mechanical Engineering, \\ Faculty of Engineering, Assiut University, Assiut 71516, EGYPT \\ E-mail: nada_ali54@yahoo.com
}

(Received November 3, 2008 Accepted November 20, 2008)

\begin{abstract}
In this study, the flow and heat transfer characteristics and the performance of double-pass flat-plate solar air heaters are studied numerically. The effects of the total air mass flow rate and the fraction of air mass flow rate in the upper or lower flow channel on the performance of the double-pass flat-plate solar air heaters have also been investigated numerically. The mathematical models that describe the flow and heat transfer characteristics of the double-pass flat-plate solar air heaters are derived from the momentum and energy conservation equations. The developed mathematical model has been solved using a finite volume discrete scheme utilizing the SIMPLE (Semi-Implicit Method for Pressure Linked Equations) pressure-correction scheme combined with QUICK (Quadratic Upwind Interpolation Convective Kinematics) scheme in the frame of staggered system. The results obtained from the numerical model are validated by comparison with experimental data of previous researchers. It has been found that there is a reasonable agreement between the present model results and those obtained by previous investigators.
\end{abstract}

KEYWORDS: Double-pass solar air heater; Thermal efficiency; Heat transfer characteristics; Performance of flat-plate collector.

\section{INTRODUCTION}

A flat-plate solar air heater is an equipment that converts solar energy into heat for generating hot air to be used for space heating [1], drying [2, 3] and paint spraying operations [4]. Solar air heaters have a number of advantages over other types including simplicity in design, ease of construction, use of cheap and locally available materials, and economical and simple operation and maintenance. Moreover, the direct use of air as the working substance reduces the number of required system components. Such heater consists of one or more sheets of glass or transparent material situated above an absorbing plate where the air flows along the plate either above or under it [5]. Flat-plate solar collectors do not have any optical concentration, therefore for a flux of incident radiation up to $1100 \mathrm{~W} / \mathrm{m}^{2}$ they are used for applications require thermal energy at moderate and low temperatures [6].

Flat-plate solar air heaters are extensively used in low temperature energy technology and have attracted the attention of a large number of investigators. Several designs of solar air heaters have been developed over the last decades in order to 
improve their performance. The major limitation of conventional type flat-plate solar air heaters is its low efficiency. The efficiency of flat-plate solar air heaters is generally low due to the low value of convective heat transfer coefficient between the absorber plate and the flowing air which leads to an increase of the absorber plate temperature, and consequently high heat losses to ambient [7].

\title{
NOMENCLATURE
}

\author{
Alphabetic Symbols \\ A channel cross-sectional area $\left(\mathrm{m}^{2}\right)$ \\ $A_{c} \quad$ collector area $\left(\mathrm{m}^{2}\right)$ \\ $c_{p} \quad$ specific heat capacity $(\mathrm{J} / \mathrm{kg} \mathrm{K})$ \\ $H \quad$ channel height (m) \\ I solar flux $\left(\mathrm{W} / \mathrm{m}^{2}\right)$ \\ $k$ thermal conductivity (W/m K) \\ $L \quad$ length of solar air heater (m) \\ $m$ mass flow rate $(\mathrm{kg} / \mathrm{s})$ \\ $N u_{x} \quad$ local Nusselt number \\ $P \quad$ pressure $(\mathrm{Pa})$ \\ $Q_{u} \quad$ useful gain of energy rate (W) \\ $r \quad$ mass fraction ratio of flow rate \\ in the upper channel to the total \\ flow rate \\ $S_{\Phi} \quad$ source term of the variable $\phi$ \\ $S_{p} \quad$ coefficient in the discretized \\ source term \\ $S_{u} \quad$ coefficient in the discretized \\ source term \\ $T \quad$ temperature $\left({ }^{\circ} \mathrm{C}\right)$ \\ $T_{a} \quad$ ambient temperature $\left({ }^{\circ} \mathrm{C}\right)$ \\ $T_{b} \quad$ bulk temperature $\left({ }^{\circ} \mathrm{C}\right)$ \\ $T_{i} \quad$ inlet temperature $\left({ }^{\circ} \mathrm{C}\right)$ \\ $T_{w} \quad$ wall temperature $\left({ }^{\circ} \mathrm{C}\right)$
}

$\begin{array}{ll}u & \begin{array}{l}\text { streamwise velocity }(\mathrm{m} / \mathrm{s}) \\ u_{i}\end{array} \\ u_{m} & \begin{array}{l}\text { inlet streamwise velocity }(\mathrm{m} / \mathrm{s}) \\ \text { cross-sectionally averaged } \\ \text { streamwise velocity }(\mathrm{m} / \mathrm{s})\end{array} \\ v & \begin{array}{l}\text { velocity in } y \text { direction }(\mathrm{m} / \mathrm{s}) \\ x\end{array} \\ \begin{array}{l}\text { Cartesian coordinate in the } \\ \text { streamwise direction }(\mathrm{m})\end{array} \\ y & \begin{array}{l}\text { Cartesian coordinate normal to } \\ \text { the wall }(\mathrm{m})\end{array}\end{array}$

\section{Greek Symbols}

$\alpha_{c} \quad$ absorptance of glass cover

$\alpha_{p} \quad$ absorptance of absorber plate

$\varepsilon_{c} \quad$ emittance of glass cover

$\varepsilon_{p} \quad$ emittance of absorber plate

$\varepsilon_{R} \quad$ emittance of bottom plate

$\phi \quad$ any of variables to be solved

$\eta_{\text {th }} \quad$ solar air heater thermal efficiency (\%)

$\Gamma_{\Phi} \quad$ diffusion coefficient of the variable $\phi$

$\mu \quad$ dynamic viscosity (Pa.s)

$\rho \quad$ density $\left(\mathrm{kg} / \mathrm{m}^{3}\right)$

$\tau_{c} \quad$ transmittance of glass cover

To achieve a considerable improvement in flat-plate solar air heaters efficiency, some techniques have been adopted to extend the area of the absorbing plate [8] or modify the flow configuration [9] have been carried out. An alternative arrangement to increase the available heat-transfer area may be achieved if air is flowing simultaneously and separately over and under the absorbing plate, instead of flowing only along one side. This definitely will lead to improved collector efficiency [10]. Garg et al. [11] indicated that double and multi-pass solar air heaters offer an extended heat transfer area and decreased overall heat losses. It has been also reported that increasing the fluid velocity by using recycle in double-pass parallel-plate heat exchangers enhances the heat-transfer coefficient, and consequently resulting in an improved performance [12-14]. Recently, very few papers have been published 
concerning the thermal performances of such systems. A double-pass solar air heater with external recycle was investigated and compared with a downward type, singlepass solar air heater by Ho et al. [13, 14]. They showed that reversing the flow order from the upper to the lower channels and vice versa in the double-pass solar air heater with external recycle has no effects on its performance.

Satcunanathan and Deonarine [15] constructed a two-pass air heater in which the air flows through the glass pane before passing through the blackened metal absorber plate. A set of performance curves of the solar air heater with two-pass flow arrangements were also developed by Wijeysundera et al. [16]. Yeh et al. [17] have studied theoretically and experimentally the performance of double-pass type solar air heaters, in which air is flowing simultaneously over and under the absorbing plate. The basic physical equations used by Yeh et al. [17] to describe the heat transfer characteristics were developed from the conservation equations of energy. The energy balances were taken under the following assumptions: the temperatures of the absorbing plate, bottom plate and bulk fluids are function of flow direction only, and both the glass covers and fluid do not absorb radiant energy. Their theoretical and experimental results showed that the double-pass solar air heater is more effective than that of heaters with only one flow channel over or under the absorbing plate. Yeh et al. [17] have also investigated theoretically and experimentally the effect of the fraction of mass flow rate in the upper or lower flow channel of a double-pass solar air heater on the collector efficiencies. Their results showed that considerable improvement in the collector performance can be obtained by employing a double-pass type solar air heater, instead of a single pass type, if the mass flow rates in both flow channels are kept the same (i.e. fraction of mass flow rate $=0.5$ ).

Naphon and Kongtragool [18] have studied numerically the heat transfer characteristics and the performance of flat-plate solar air heaters. Their mathematical models have been solved by the explicit method of finite-difference scheme. Five different configurations of solar air heaters were considered in this study. The results show that the conventional solar air heater with a single glass cover gives the lowest thermal efficiency because in such configuration both forced convection and radiative heat losses are dominant. On the other hand, the results indicate that the thermal performance of the double-pass solar air heater is much higher because of the employment of both sides of the absorber plate in the heat transfer process as well as the sensible reduction in the overall losses compared to that of the conventional one.

As described above, there are many studies that have been conducted on the performance of solar air heaters. However, accurate studies on the heat transfer characteristics and performance of the double-pass flat plate solar air heater which consider variation of air properties with temperature and based on simultaneous solution of both the momentum and the energy conservation equations are still very limited or do not exist for the best of the author's knowledge. The objective of present work is to study numerically the flow and heat transfer characteristics and the performance of the double-pass flat plate solar air heaters under different operating conditions. Moreover, the effects of various relevant parameters such as the total air mass flow rate and the air mass fraction on the collector performance are also investigated. For this purpose, a finite volume discrete scheme using the SIMPLE pressure-correction scheme combined with QUICK scheme in the frame of staggered grid is used. 


\section{MODEL PROBLEM AND DISCRETIZATION}

\subsection{Governing Equations}

The system to be studied is a double-pass type solar air heater of a width $=1 \mathrm{~m}$ shown in Fig. 1. Two air streams of different flow rates but with fixed total flow rate are flowing steadily and simultaneously through two separate channels (above and below the absorber plate) for heating. The process is modeled by solving the two-dimensional momentum, and energy conservation equations in the upper and lower channels.

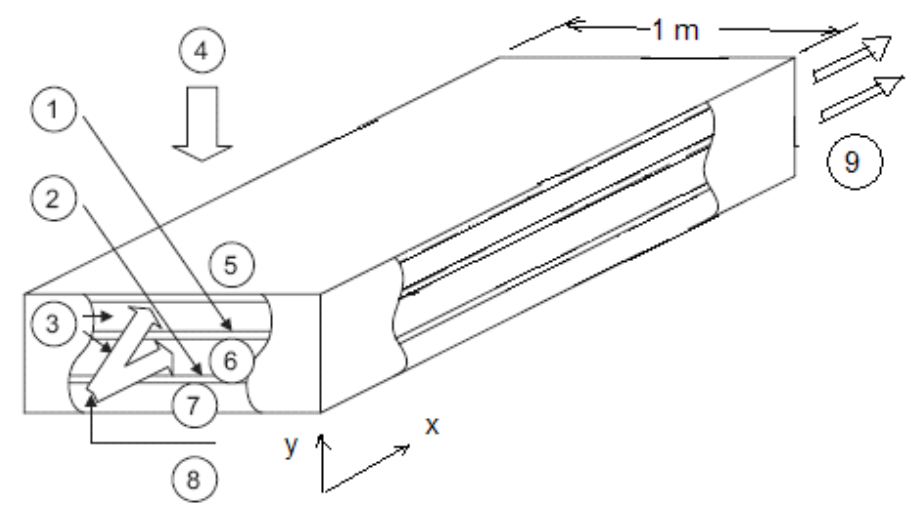

Fig. 1: Schematic sketch of the double-pass solar air heater. (1) Absorbing plate, (2) Bottom plate, (3) Air gap, (4) Solar radiation, (5) Glass cover, (6) Air flow channel, (7) Insulation, (8) Inlet air, and (9) Outlet air

\subsubsection{Flow Model}

For two dimensional, incompressible, steady laminar channel flows; the continuity and momentum equations are given as [19];

$$
\begin{aligned}
& \frac{\partial u}{\partial x}+\frac{\partial v}{\partial y}=0 \\
& \frac{\partial(\rho u u)}{\partial x}+\frac{\partial(\rho v u)}{\partial y}-\frac{\partial}{\partial x}\left[\mu\left(\frac{\partial u}{\partial x}\right)\right]-\frac{\partial}{\partial y}\left[\mu\left(\frac{\partial u}{\partial y}\right)\right]+\frac{\partial P}{\partial x}=0 \\
& \frac{\partial(\rho u v)}{\partial x}+\frac{\partial(\rho v v)}{\partial y}-\frac{\partial}{\partial x}\left[\mu\left(\frac{\partial v}{\partial x}\right)\right]-\frac{\partial}{\partial y}\left[\mu\left(\frac{\partial v}{\partial y}\right)\right]+\frac{\partial P}{\partial y}=0
\end{aligned}
$$

where, $u$ and $v$ are the streamwise and transverse velocity components, respectively. $\rho$ and $\mu$ are the fluid density and dynamic viscosity, respectively. $P$ is the fluid pressure.

\subsubsection{Energy Transfer Model}

For two dimensional, incompressible, steady laminar channel flows; the energy equation (when the specific heat at constant pressure is assumed constant) is given as [19]: 


$$
\frac{\partial(\rho u T)}{\partial x}+\frac{\partial(\rho v T)}{\partial y}-\frac{\partial}{\partial x}\left[\frac{k}{c_{p}}\left(\frac{\partial T}{\partial x}\right)\right]-\frac{\partial}{\partial y}\left[\frac{k}{c_{p}}\left(\frac{\partial T}{\partial y}\right)\right]=0
$$

where $k$ and $c_{p}$ are the fluid thermal conductivity and specific heat at constant pressure, respectively. $T$ is the fluid temperature.

\subsection{Discretization}

The steady-state form of the conservation equations of continuity, momentum, and energy can be written in a general form as [20];

$$
\frac{\partial(\rho u \phi)}{\partial x}+\frac{\partial(\rho v \phi)}{\partial y}-\frac{\partial}{\partial x}\left[\Gamma_{\phi}\left(\frac{\partial \phi}{\partial x}\right)\right]-\frac{\partial}{\partial y}\left[\Gamma_{\phi}\left(\frac{\partial \phi}{\partial y}\right)\right]-S_{\phi}=0
$$

where $\phi$ stands for any of the variables to be solved, $\Gamma_{\Phi}$ is the diffusion coefficient, and $S_{\Phi}$ is the source term of the variable $\phi$. For $\phi=u$ or $v, \Gamma_{\Phi}=\mu$ and $S_{\Phi}=$ pressure gradient in the flow direction one gets the momentum equations, while for $\phi=1, \Gamma_{\Phi}=0$ and $S_{\Phi}$ $=0$ one obtains the continuity equation. If $\phi=T, \Gamma_{\Phi}=k / c_{p}$ and $S_{\Phi}=0$ one gets the energy equation [20].

Specification of control volume (CV) and the geometrical arrangement of the nine grid points to be used in the QUICK scheme are given in Fig. 2, in which the grid has been staggered so that the velocity grid points are located mid-way between the scalar grid points. The $\phi$ cells serve as grid points to store all scalar variables (pressure and temperature). All the governing equations are discretised by first integrating them over a CV and then approximating the fluxes of the considered variable crossing every face of each cell in terms of the variable values at the neighboring grid points. In the present work, a QUICK scheme, which can handle uniform and non-uniform grid systems, is used to finite differencing the convective terms and to secure second order accuracy in central differencing of the diffusive fluxes. The resulting finite-difference equations are described in the form of [20]

$$
a_{p} \phi_{p}=\sum_{i} a_{i} \phi_{i}+S_{u} \Delta V, \quad i=E, W, N, S, E E, W W, N N, S S,
$$

where $a_{p}=\sum_{i} a_{i}-S_{p} \Delta V, \quad i=E, W, N, S, E E, W W, N N, S S$,

is the coefficient at the considered grid point and $E, W, N, S, E E, W W, N N, S S$ stand for the east, west, north, east of east, west of west, north of north and south of south neighboring grid points, respectively as shown in Fig. 2. The cell volume is $\Delta V$, and $S_{p}$ and $S_{u}$ are the coefficients appearing in the following linearized source term;

$$
S_{\phi}=S_{u}+S_{p} \phi
$$

The finite difference coefficients $a_{i}$ are the coefficients describing the magnitudes of the sum of the convective and diffusive fluxes and account for the geometric properties of the control volume. They forms of these coefficients are similar to those given by Abdel-Rahman [21]. 


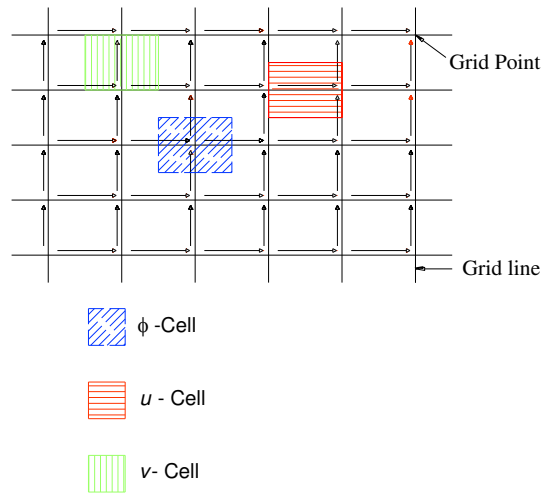

(a)

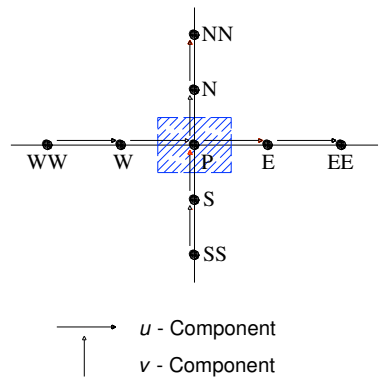

(b)

Fig. 2: (a) Control volume specification and (b) Geometrical arrangement of the nine points used for the QUICK scheme [21].

\subsection{Computational Domain and Grid System}

The physical problem considered in the present study is a steady state laminar channel flow. Figure 1 displays the flow channel geometry and the coordinate system used for the considered problem. The computations are carried out in the rectangular domain shown in Fig. 3. One of the important points of numerical solution is the choice of grid point system for which the equations are discretised. In relation with the use of the SIMPLE scheme, a staggered grid is used in this work as described in [22]. A nonuniform grid system was employed and the grid density was made higher near the leading edge of the absorbing plate in the $x$ direction and near the walls in the $y$ direction to take into account the steep change of velocity, and temperature there. A grid-dependence analysis of the method of solution was performed. Grid points of total number of $200 \times 72$ have been allocated in the computational domain. The number of elements is chosen to be $14,400(200 \times 72)$ because further refinement of the mesh to 20,000 elements produced just a $0.3 \%$ difference in $\eta_{t h}$.

The use of the staggered grid system leads to difficulty in solving Eq. (6) for the cells near the surfaces and corners of the absorbing plate, and therefore the finite difference equations need be revised there. The coefficients of the finite difference equations are revised at those locations before the computation of Eq. (6) is executed. An outline of the revisions of the coefficient is given in great details by Xi [23].

\subsection{Boundary Conditions}

The boundary conditions of the problem as shown in Fig. $\mathbf{3}$ are:

1- At the inlet, the streamwise velocity is assumed to be uniform and equals $u_{\mathrm{i}}$, the transverse velocity is assumed to be zero, and a constant inlet temperature of $T_{i}$ is specified.

2- At the bottom wall, collector cover and absorbing plate upper and lower sides, $u$ and $v$ are set to zero. The absorbing plate, glass cover and bottom wall temperatures are assumed to vary in the flow direction only. These temperatures were obtained from a balance of the radiative and convective heat fluxes. The temperature boundary conditions are given by; 


$$
\begin{aligned}
& q_{C}=+k(\partial T / \partial y)_{c}=I \alpha_{c}+h_{r, p-c}\left(T_{p}-T_{c}\right)-h_{a}\left(T_{c}-T_{a}\right)-h_{r, c-a}\left(T_{c}-T_{a}\right) \\
& q_{U}=-k(\partial T / \partial y)_{u, p}=I \alpha_{p} \tau_{c}-h_{r, p-c}\left(T_{p}-T_{c}\right)-h_{r, p-R}\left(T_{p}-T_{R}\right)-q_{L} \\
& q_{L}=+k(\partial T / \partial y)_{l, p}=I \alpha_{p} \tau_{c}-h_{r, p-c}\left(T_{p}-T_{c}\right)-h_{r, p-R}\left(T_{p}-T_{R}\right)-q_{U} \\
& q_{R}=-k(\partial T / \partial y)_{R}=h_{r, p-R}\left(T_{p}-T_{R}\right)-U_{R}\left(T_{R}-T_{a}\right)
\end{aligned}
$$

where $h_{r, p-c}$ and $h_{r, p-R}$ are the radiative heat transfer coefficients between absorbing plate and glass cover and bottom plate, respectively. These radiation coefficients between the air duct surfaces may be estimated by assuming a mean radiant temperature equal to the mean fluid temperature [17], viz

$$
\begin{aligned}
& h_{r, p-c}=4 \sigma T_{u, f m}^{3} /\left[\left(1 / \varepsilon_{p}\right)+\left(1 / \varepsilon_{c}\right)-1\right], \\
& h_{r, p-R}=4 \sigma T_{l, f m}^{3} /\left[\left(1 / \varepsilon_{p}\right)+\left(1 / \varepsilon_{R}\right)-1\right],
\end{aligned}
$$

while that from glass cover to the ambient

$$
h_{r, c-a}=\varepsilon_{c} \sigma\left(T_{c, m}^{2}+T_{a}^{2}\right)+\left(T_{c, m}+T_{a}\right) \text {, }
$$

where $\sigma$ is the Stefan-Boltzman constant, $T_{u, f m}$ and $T_{l, f m}$ are the upper channel and lower channels fluid average temperatures, respectively. $T_{c, m}$ and $T_{a}$ are the cover average temperature and ambient air temperature, respectively. $\varepsilon_{p}, \varepsilon_{c}$, and $\varepsilon_{R}$ are the emittance of the plate, glass cover and bottom plate, respectively. $\alpha_{p}$, and $\alpha_{c}$, are the absorptance of the plate and glass cover, respectively. $U_{R}$ is the loss coefficient from the bottom of the solar collector to the ambient. The convective heat transfer coefficient for air flowing over the outside surface of glass cover, $h_{a}$, is calculated by the following empirical equation given by McAdam [24].

$$
h_{a}=5.7+3.8 \mathrm{~V} \text {, }
$$

where $V$ is the wind velocity in $\mathrm{m} / \mathrm{s}$.

3- At the channels exit, the gradients of both the flow and temperature fields are set to zero or assumed to obey the boundary layer approximation. This treatment of the down stream end boundary condition has proved to be robust and effective in shortening the computational domain [22].

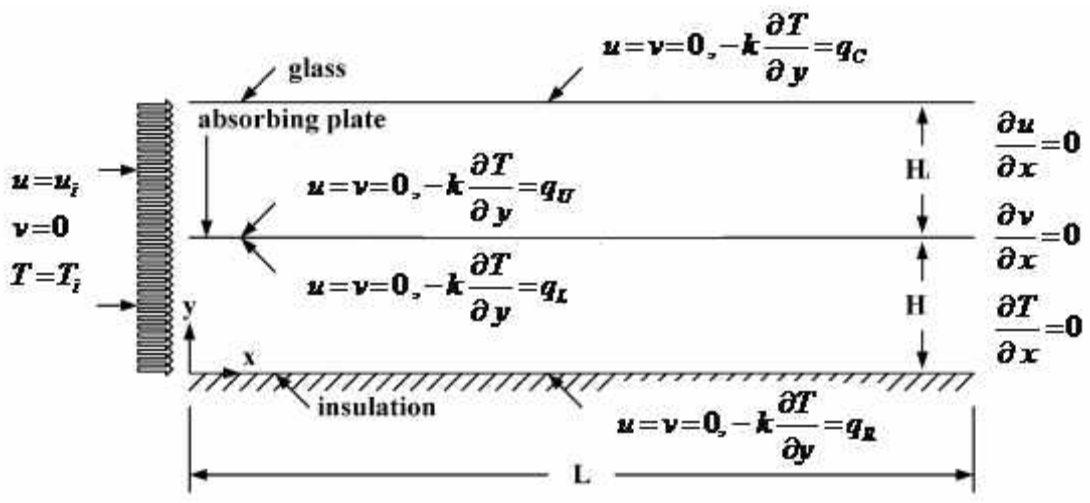

Fig. 3: Boundary conditions. 


\subsection{Numerical Procedure}

The present study utilizes a modified version of the SIMPLE procedures developed by Partaker and Spalding [20]. The main steps of the SIMPLE algorithm are;

1. A pressure field is assumed,

2. It is used to obtain approximate velocity field,

3. The velocity and pressure fields are corrected if the former does not satisfy the continuity equation,

4. Solve the discretization equations for the other $\phi$ 's such as temperature provided its influence on the flow field.

5. Return to step 2 with the corrected velocity field and the new values of all other $\phi$ 's and then the processes 2-4 are repeated until a converged solution is obtained.

In the present work, the cross-stream distribution of $u$-velocity component is adjusted to satisfy the overall continuity (conservation of the mass flow are integrated over a cross-stream line) whereas the pressure field is adjusted to satisfy the overall momentum balance. This procedure is important for the present problem in which the flow is changed as the flow moves downstream [22].

An alternating direction implicit (ADI) procedure, which has been developed by Abdel-Rahman and Suzuki [22], has been combined with the iterative solution procedure of Eq. (6) to enhance isotropic propagation of a change of variables occurring at one point to the surrounding. This procedure makes use of the line-by-line Tri-Diagonal Matrix Algorithm (TDMA) solver. In the ADI procedure, sweep of lineby-line integration was carried out along both north-south grid lines and along eastwest grid lines alternatively. The same procedure was applied twice for the pressure correction [22].

\subsection{Definition of Performance Parameters}

Calculations were carried out in order to evaluate the effect of air mass flow rate and air mass fraction on the heat transfer characteristics and performance of a solar air heater shown schematically in Fig. 1. In this heater, an absorbing plate divides the air passage into two equivalent channels. Thus, the configuration considered in this simulation study is a double-pass in which the air is flowing over and under the absorbing plate as shown in Figs. 1 and 2. As for heat transfer characteristics of the considered solar air heater, the local heat transfer coefficient in term of local Nusselt number, $N u_{x}$, of laminar sublayer adjacent to walls surface is given by [24];

$$
N u_{x}=\frac{2 H q_{w}}{k\left(T_{w}-T_{b}\right)}=\frac{2 H(\partial T / \partial y)_{\text {atwall }}}{\left(T_{w}-T_{b}\right)}
$$

where

$$
T_{b}=\frac{1}{A u_{m}} \int_{A} u T d A,
$$

is the fluid bulk mean temperature in the upper or lower channels, $A$ is the channel cross-sectional area, $u_{m}$ is the cross-sectionally averaged streamwise velocity, $T_{w}$ is the wall temperature, and $H$ is the channel height. 
The solar air heater thermal efficiency, $\eta_{t h}$, in this study is calculated from the useful gains of energy rate brought out by fluid 1 and fluid 2 in the upper- and lowerflow channels, respectively, as;

$$
\begin{aligned}
& Q_{\text {upper }}=m r c_{p}\left(T_{b-\text { upper }}-T_{i}\right) \\
& Q_{\text {lower }}=m(1-r) c_{p}\left(T_{b-\text { lower }}-T_{i}\right)
\end{aligned}
$$

where $m$ is the air mass flow rate, and $r$ is the air mass fraction. $T_{b \text {-upper }}$ and $T_{b \text {-lower }}$ are the upper- and lower-bulk mean temperatures at the exit of each channel, respectively.

The total rate of energy gain is:

$$
Q_{u}=Q_{\text {upper }}+Q_{\text {lower }}
$$

and thus, the solar air heater thermal efficiency is obtained as given in [17] from:

$$
\eta_{t h}=\frac{Q_{u}}{I A_{c}}
$$

where $A_{c}$ is the surface area of the collector.

\section{RESULTS AND DISCUSSION}

The above described model was applied to a double-pass solar air heater as described above and whose dimensions comprise of $L=0.30 \mathrm{~m}, H=0.0275 \mathrm{~m}$ and the channel width $=1 \mathrm{~m}$. Series of numerical simulations were performed to study the effects of varying the controlling parameters such as the total air mass flow rate and the air mass fraction on the performance of this heater. The total air mass flow rates considered are 0.0050, 0.0107, 0.0161, 0.0214 and $0.0250 \mathrm{~kg} / \mathrm{s}$ (Reynolds number ranges from $115 \mathrm{up}$ to 2100), and air mass fraction of 0.1, 0.2, 0.3, 0.4, 0.5, 0.6, 0.7 and 0.8. Air at a uniform temperature of $T_{i}=30^{\circ} \mathrm{C}$ is introduced at the inlet of the solar air heater. The absorbing plate is exposed to a uniform solar flux of 830 and $1100 \mathrm{~W} / \mathrm{m}^{2}$. The optical properties of the absorbing plate, the glass cover and the bottom plate are: $\alpha_{\mathrm{p}}=0.96, \alpha_{\mathrm{c}}$ $=0.05, \varepsilon_{\mathrm{p}}=0.8, \varepsilon_{\mathrm{c}}=0.94, \tau_{\mathrm{c}}=0.96$ and $\varepsilon_{\mathrm{R}}=0.875$. The wind velocity is taken to be 1 $\mathrm{m} / \mathrm{s}$. The lower plate which is the collector casing is insulated (i.e. $U_{R} \approx 0$ ). The obtained results are presented and discussed below.

Figure 4 (a) shows the streamwise velocity profiles at different axial positions along the upper and lower channels obtained for solar intensity of $1100 \mathrm{~W} / \mathrm{m}^{2}$, air mass flow rate of $0.0107 \mathrm{~kg} / \mathrm{s}$ and air mass fraction of 0.5. The results presented in Fig. 4 (a) indicate that the flow is developing as it moves downstream towards the end of the collector in both the upper and lower channels. Figure 4 (b) shows the streamwise velocity profiles obtained for the same conditions but for different air mass fractions at an axial position of $x / L=0.9$. The figure illustrates that the velocity in the upper channel is getting higher while that in the lower channel is getting lower as the mass fraction is increased. In every case, the streamwise velocity distribution is parabolic since the flow is always laminar in both channels (Reynolds number is about 500 in this case). 


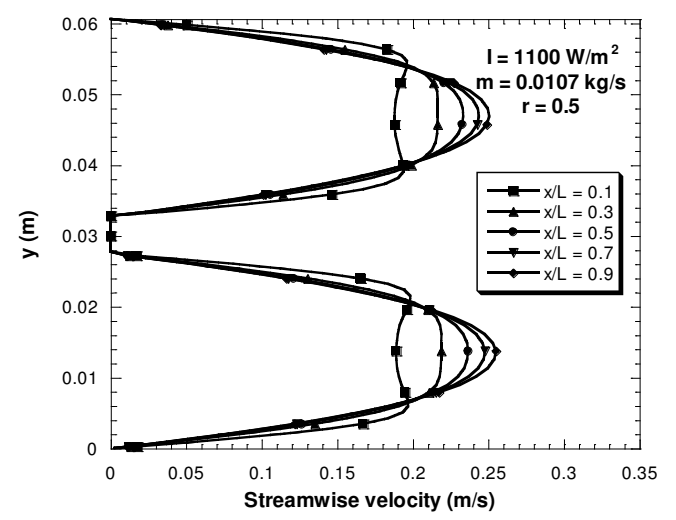

(a)

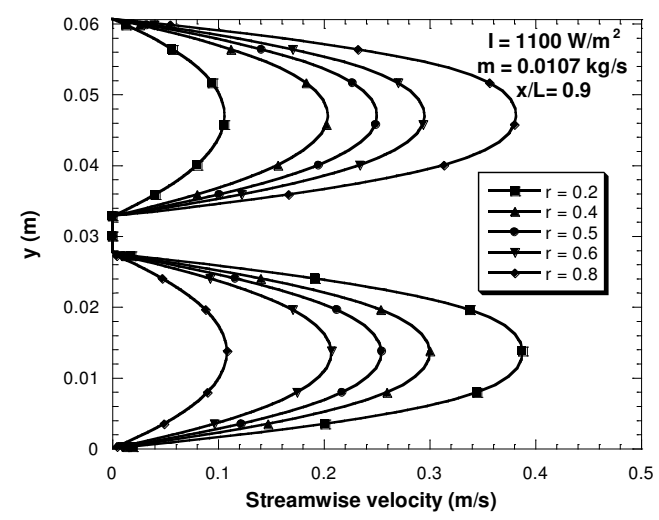

(b)

Fig. 4: Streamwise velocity profiles at different axial positions.

Figure 5 (a) shows the air temperature profiles at different axial positions along the upper and lower channels obtained for solar flux of $1100 \mathrm{~W} / \mathrm{m}^{2}$, air mass flow rate of $0.0107 \mathrm{~kg} / \mathrm{s}$ and air mass fraction of 0.5 . The obtained results show that the fluid temperature is developing as it moves downstream towards the end of the collector in both the upper and lower channels. The figure also shows that the temperature polarization is very high at every axial position. Figure 5 (b) shows the temperature profiles obtained for the same conditions but for different air mass fractions at axial position of $x / L=0.9$. It is clear that fluid temperatures are high for low air mass flow rate. Figures 5 (a) and (b) illustrate that the fluid temperatures are high near absorbing plate surfaces, glass cover and bottom wall due to low velocities of the adjacent boundary layers which result in a low cooling rate at such velocities compared with the rest of the flow channels.

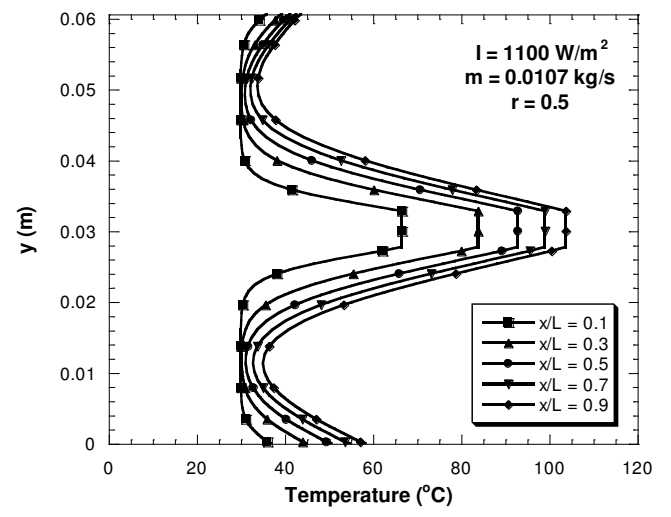

(a)

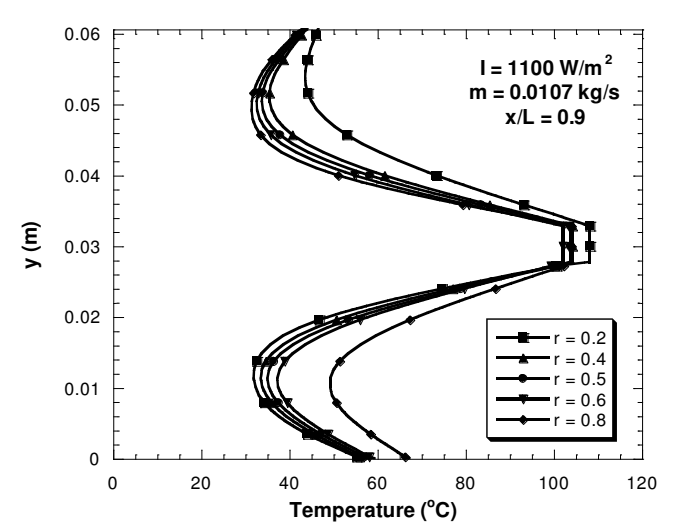

(b)

Fig. 5: Temperature profiles at different axial positions.

Figure 6 shows the axial distribution of the air bulk mean temperatures in the upper and lower channels along with the axial distribution of the surface temperatures at the bottom wall, collector cover and the upper- and lower-side of absorbing plate 
obtained for solar flux of $1100 \mathrm{~W} / \mathrm{m}^{2}$, air mass flow rate of $0.0107 \mathrm{~kg} / \mathrm{s}$ and air mass fraction of 0.5 . The figure shows that the absorbing plate lower side temperature is slightly higher than the upper side temperature in this case. On the other hand, the bottom wall temperature is higher than the collector cover. This can be attributed to the fact that the collector cover and consequently the upper channel is losing heat to ambient air by convection and radiation, while the losses from the lower channel are less because of the insulation of its bottom wall. This explains the slight difference found between the bulk mean temperatures in the upper and lower channel to the favor of the lower channel as shown in the figure.

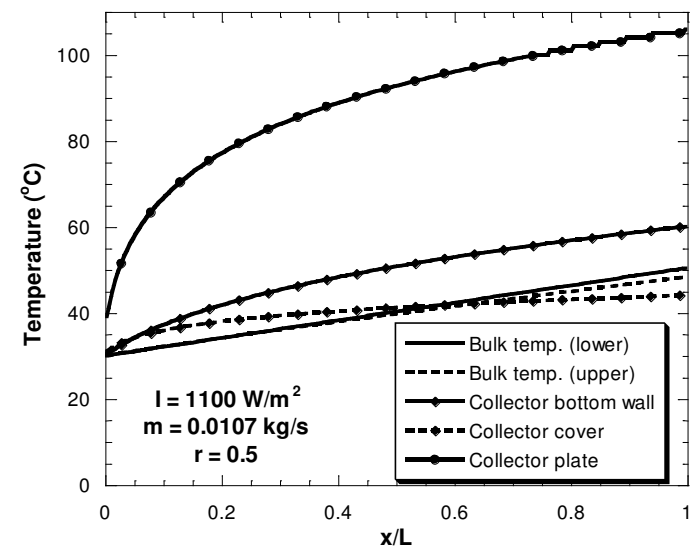

Fig. 6: Axial distributions of fluid and surface temperatures.

The key parameter responsible for improving the efficiency of solar air heaters is the convective heat transfer coefficient between the absorber plate and the flowing air. Figure 7 shows the local Nusselt number along the upper (Fig. 7 (a)) and lower (Fig. 7 (b)) sides of the absorbing plate obtained for solar flux of $1100 \mathrm{~W} / \mathrm{m}^{2}$, air mass flow rate of $0.0107 \mathrm{~kg} / \mathrm{s}$ and air mass fraction of $0.3,0.5$, and 0.7 . Figure 7 shows that the local Nusselt number (in both the upper and lower channels) decreases as the flow moves downstream towards the end of the collector. The local Nusselt number decreases asymptotically as the flow moves downwards reaching a value of about 10.0 close to the fully developed value of 8.235 for similar geometrical and operating parameters [25]. The fully developed value of Nusselt number could not be reached in this study as the length of the collector is very short $(L=0.3 \mathrm{~m})$.

Figure 7 (a) shows that the local Nusselt number in the upper channel increased as the mass fraction is increased due to the increase in the temperature gradient with the mass fraction there (see Fig. 5 (b)). On the other hand, Figure 7 (b) shows that the local Nusselt number in the lower channel decreased as the mass fraction is decreased due to the decrease in the temperature gradient with the mass fraction there (see Fig. 5 (b)). The figures also show that the local Nusselt number in the upper and lower channels is almost the same when the mass fraction equals 0.5 .

Figure 8 shows the rate of heat gain brought out by air flowing in the upper and lower channels at different air mass fractions calculated using Eq. (9). These results were obtained for solar fluxes of 830 and $1100 \mathrm{~W} / \mathrm{m}^{2}$, and air mass flow rates of 
$0.0107,0.0161$, and $0.0214 \mathrm{~kg} / \mathrm{s}$. It shows that the heat gain in the upper channels is increased as the air mass fraction is increased for the entire air mass flow rates considered in this study. Comparison between the values obtained for solar fluxes of 1100 and $830 \mathrm{~W} / \mathrm{m}^{2}$ shows that the rate of heat gain in the upper and lower channels are increased as solar flux is increased.

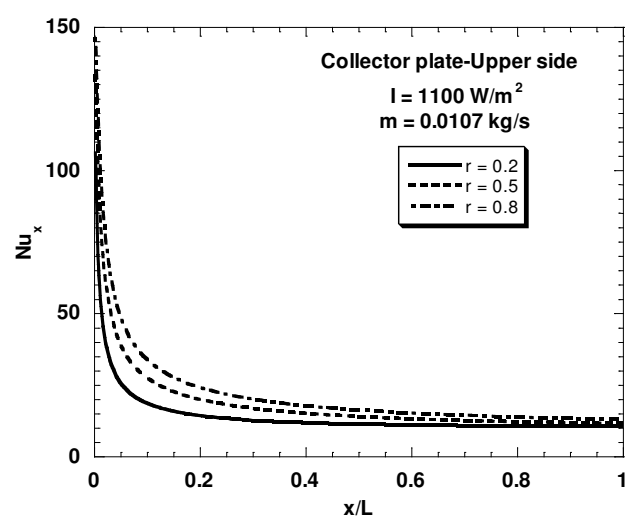

(a)

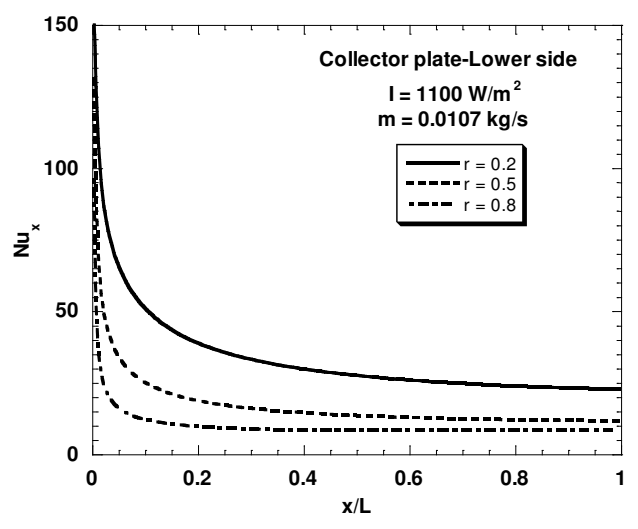

(b)

Fig. 7: Local Nusselt number axial distribution.

Figure 8 also shows that the rate of energy gain brought out by air flowing in the lower channel is larger than that brought out by air flowing in the upper channel for the smaller air mass fractions considered. This could be explained by the higher air mass flow rate in the lower channel compared with that in the upper channel for the smaller air mass fractions. Figure 8 (a) shows that the rate of heat gain brought out by air flowing in the upper channel tends to increase as the mass fraction is increased. Again, this can be explained by the increase of the air mass flowing in the upper channel as the air mass fraction is increased.

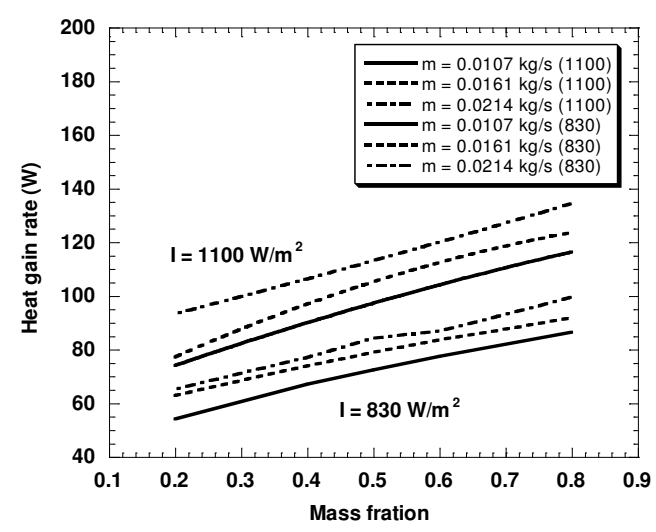

(a) Upper channel

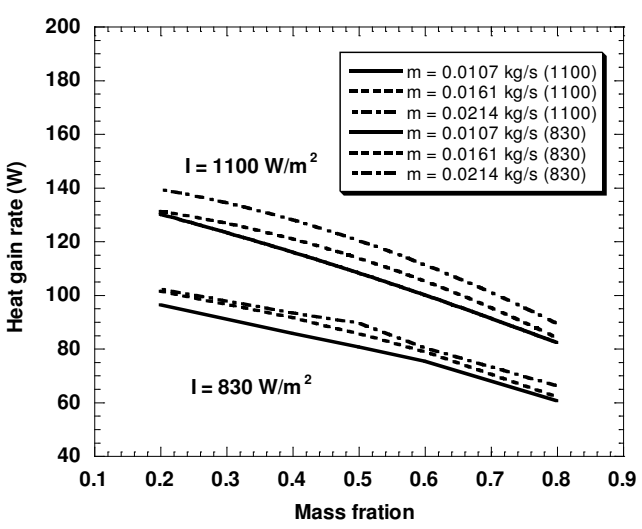

(b) Lower channel

Fig. 8: Rate of energy gain brought out by air flowing. 
Figure 9 shows the thermal efficiency of the solar air heater at different air mass fractions calculated using Eq. (10). These results were obtained for solar fluxes of 830 and $1100 \mathrm{~W} / \mathrm{m}^{2}$, and air mass flow rates of $0.0107,0.0161$, and $0.0214 \mathrm{~kg} / \mathrm{s}$. The experimental and theoretical results of Yeh et al. [17] are also shown along with those obtained in the present study. The results of the present model indicate that the thermal efficiency increases with the increase of mass flow rate and mass fraction up to mass fraction of 0.5. Figure 9 shows that the thermal efficiency variation with mass fraction reasonably agrees with that determined experimentally and theoretically in [17] particularly at low air mass flow rates. Moreover, the figure indicates that except for the case of intermediate mass flow rate $(0.0161 \mathrm{~kg} / \mathrm{s})$, the predicted thermal efficiency agrees reasonably with the experimental and theoretical values at the whole range of mass fractions considered in this study, for the higher solar flux $\left(I=1100 \mathrm{~W} / \mathrm{m}^{2}\right)$ and lower solar flux $\left(I=830 \mathrm{~W} / \mathrm{m}^{2}\right)$.

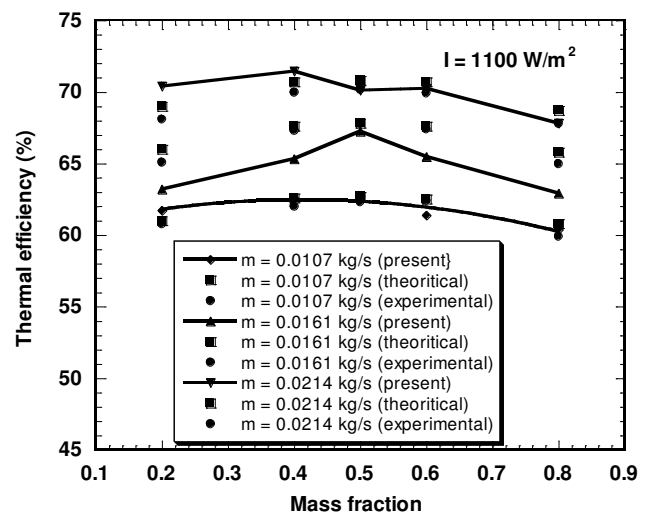

(a)

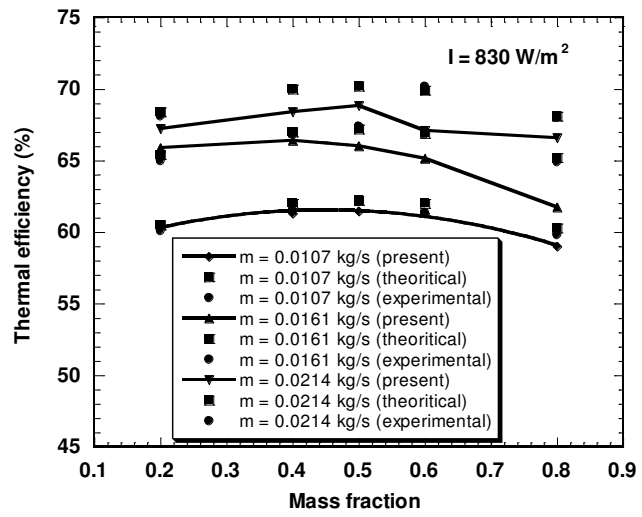

(b)

Fig. 9: Thermal efficiency of the solar air heater.

\section{CONCLUSIONS}

In this study, the flow and heat transfer characteristics of double-pass flat-plate solar air heaters are investigated numerically. The effects of the total air mass flow rate and the fraction of air mass flow rate in the upper and lower flow channel on the performance of the double-pass flat-plate solar air heaters have also been investigated numerically. The mathematical models that have been used to achieve the objective of the present study were derived from the momentum and energy conservation equations. The elliptic type of the governing equations was solved using the SIMPLE pressurecorrection algorithm for pressure field in connection with the high order QUICK scheme. The alternating direction implicit ADI scheme, which makes use of the TDMA in solving the resulting coefficient matrix, was used to solve the governing equations to reduce the number of iterations. A scheme to secure the overall mass conservation was also employed. The following points can be drawn from the results of numerical simulation: 
- The obtained results of the flow and heat transfer characteristics in the doublepass flat-plate solar air heater reasonably agree with previous experimental and theoretical results.

- The obtained results can be used to evaluate the heat and mass flow characteristics and asses the performance of the double-pass flat-plate solar air heater under different operating conditions.

- The present code can be easily applied and used to predict with acceptable degree of accuracy the performance of the double-pass and multi-pass flatplate solar air heaters under different operating conditions.

\section{REFERENCES}

1. Badescu V., and Sicre B., Renewable energy for passive house heating. Part I. Building description, Energy and Buildings, Vol. 35, No. 11, pp. 1077-1084, 2003.

2. El-Sebaii A.A., Aboul-Enein S., Ramadan M.R.I., and El-Gohary H.G., Empirical correlations for drying kinetics of some fruits and vegetables, Energy, Vol. 27, No. 9, pp. 845-859, 2002.

3. Ekechukwu O.V., and Norton B., Review of solar-energy drying systems III: low temperature air-heating solar collectors for crop drying applications, Energy Conversion and Management, Vol. 40, No. 6, pp. 657-667, 1999.

4. Rincon M.E., Jimenez A., Orihuela A., and Martinez G. Thermal treatment effects in the photovoltaic conversion of spray-painted $\mathrm{TiO} 2$ coatings sensitized by chemically deposited CdSe thin films, Solar Energy Materials and Solar Cells, Vol. 70, No. 2, pp. 163-173, 2001.

5. Liu C. H., and Sparrow E.M., Convective-radiative interaction: a parallel plate channel-application to air-operated solar collectors, Int. J. Heat Mass Transfer, Vol. 23, No. 8, pp. 1137-46, 1980.

6. Duffie J. A., and Beckman W.A., Solar engineering of thermal processes, New York: Wiley; 1980.

7. Ahmad A., Saini J. S., and Varma H. K., Effect of geometrical and thermophysical characteristics of bed materials on the enhancement of thermal performance of packed bed solar air heaters, Energy Conversion and Management, Vol. 36, No. 12, pp. 1185-1195, 1995.

8. Yeh H.M., Theory of baffled solar air heaters, Energy, Vol. 17, No. 7, pp. 697$702,1992$.

9. Yeh H.M., and Lin T.C., The effect of collector aspect ratio on the collector efficiency of flat-plate solar air heaters, Energy, Vol. 20, No. 10, pp. 1041-1047, 1995.

10. Verma R., Chandra R., and Garg H.P., Optimization of solar air heaters of different designs, Renewable Energy, Vol. 2, No. 4-5, pp. 521-531, 1992.

11. Garg H.P., Sharma V.K., and Bhargava A.K., Theory of multiple-pass solar air heaters, Energy, Vol. 10, No. 5, pp. 589-599, 1985.

12. Yeh H.M., Ho C.D., and Sheu W.S., Double-pass heat and mass transfer through a parallel-plate channel with recycle, Int J. Heat Mass Transfer, Vol. 43, No. 3, pp. 487-491, 2000. 
13. Ho C.D., Yeh H.M., and Sheu W.S., An analytical study of heat and mass transfer through a parallel-plate channel with recycle, Int. J Heat Mass Transfer, Vol. 41, No. 17, pp. 2586-2599, 1998.

14. Ho C.D., Yeh H.M., and Sheu W.S., The influence of recycle on double-pass heat and mass transfer through a parallel-plate device, Int. J. Heat Mass Transfer, Vol. 42, No. 9, pp. 1707-1722, 1999.

15. Satcunanathan S., and Deonarine S.A. A two-pass solar air heater, Solar Energy, Vol. 15, No. 1, pp. 41-59, 1973.

16. Wijeysundera N.E., Ah L.L., and Tjioe L.E., Thermal performance study of twopass solar air heaters, Solar Energy, Vol. 28, No. 5, pp. 363-370, 1982.

17. Yeh H.M., Ho C.D., and Hou J.Z., The improvement of collector efficiency in solar air heaters by simultaneously air flow over and under the absorbing plate, Energy, Vol. 24, No. 10, pp. 857-871, 1999.

18. Naphon P, and Kongtragool B. Theoretical study of heat transfer characteristics and performance of the flat-plate solar air heaters. Int. Comm. Heat Mass Transfer, Vol. 30, No. 8, pp. 1125-1136, 2003.

19. Anderson, D.A., Tannehill, J.C. and Pletcher, R.H. Computational fluid mechanics and heat transfer, Hemisphere Publishing Corporation' New-York; 1984.

20. Patankar, S. V. and Spalding, D. B., A calculation procedure for heat, mass and momentum transfer in three-dimensional parabolic flows, Int. J. Heat Mass Transfer, Vol. 15, No. 8, pp. 1787-1806, 1972.

21. Abdel-Rahman, A. K. Flow and heat transfer characteristics of internal flows with fluid injection, Ph.D. thesis, Kyoto University, Kyoto, Japan; 1992.

22. Abdel-Rahman, A. K. and Suzuki, K., Laminar channel flow with fluid injection accounting for the flow in the porous wall, Proceedings of the 5th Int. Conference of Fluid Mechanics, Cairo, pp. 367-379, 1995.

23. Xi, G., Flow and heat transfer characteristics of fin arrays in the low and middle Reynolds number ranges, Ph.D. thesis, Kyoto University, Kyoto, Japan; 1991

24. McAdams W.H., Heat transmission, New York, McGraw-Hill, 1954.

25. Sadik Kakac, Ramesh K. Shah and Win Aung, Handbook of single-phase convective heat transfer, Wiley-Interscience Publication, New York, 1987. 


\title{
دراسة عددية لخصائص انتقال الحرارة والأداء لسخان هواء شمسي مسطح ثنائي السريان
}

\author{
على كامل عبد الرحمن \\ قسم الهنسة الميكانيكية - كلية الهندسة \\ جامعة أسيوط - أسيوط 71516 - جمهورية مصر العربية
}

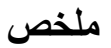

في هذه الورقة، نم اعداد نموذج رياضي عددي لدراسة خصائص السريان وتقييم انتقال الحرارة والأداء

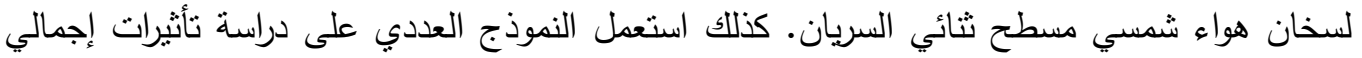

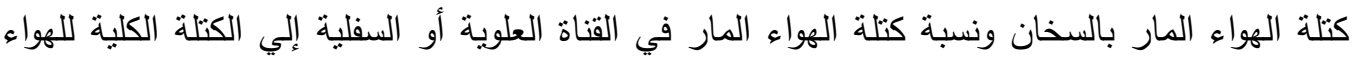
على أداء السخان. النموذج الرياضي المستخدم والذي يصف خصائص السريان وانتقال الحرارة لسخان الهواء الثمسي المسطح ثنائي السريان تم استتباطه من معادلات حفظ كمية الحركة والطاقة. هذا النموذج الرياضي المستتبط نم حله عدديا باستخدام طريقة الحجوم المحدودة (Finite Volume) والتي تنتهج لنهان

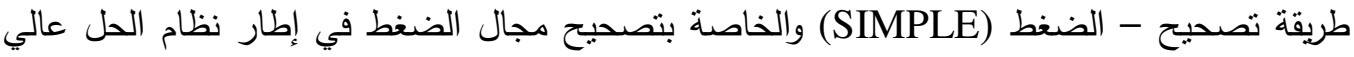

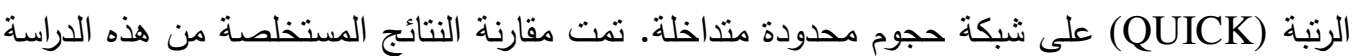

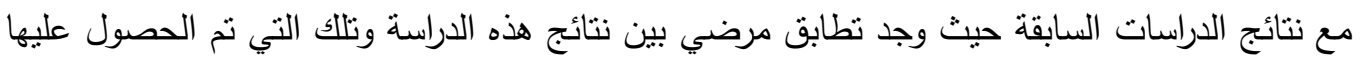
في هذه الدراسات. 